\title{
Image on composite materials
}

\author{
Minodora Maria Pasare ${ }^{1}$ and Nicoleta Maria Mihut ${ }^{1}$ \\ ${ }^{1}$ Industrial Engineering and Automatic Department, "Constantin Brancusi" University of \\ Targu-Jiu, Romania
}

E-mail: mihut.nicoleta@gmail.com

\begin{abstract}
Composite materials are materials with remarkable properties, obtained by combining two or more homogeneous macroscopic materials, with different structure and properties, which, by combining the individual qualities of the components, form a heterogeneous material with improved overall performance. A special category in the composite materials class is represented by thin layer deposits. Composite material deposits have a long history in the back. They have been used since ancient times and have evolved with society. There are several classification criteria according to the process of obtaining, according to the nature of the components, according to their functional role, etc. The advantages presented by the composite materials make them to be used in various fields such as aerospace, metallurgical, medical, etc. and to be considered the materials of the future.
\end{abstract}

Keywords: Composite materials, advantages, classification

\section{Introduction}

Over time, the society has evolved also due to scientific and technical progress. To this fact also contributed the ability of materials science to design and use new materials obtained by combining several elements, so that materials with remarkable properties were obtained. This category also includes composite materials.

\section{General considerations}

The composite material is an assembly consisting of two or more homogeneous macroscopic materials, with different structure and properties, which, by combining the individual qualities of the components, form a heterogeneous material with improved overall performance.

Therefore, a composite consists of at least two components, one of which has a matrix function, the other being embedded in the first, in different forms: with reinforcement role, with well contoured separation surfaces, fine or colloidal dispersed.

Figure 1 shows a material composite scheme, which is evident in the two component parts: the matrix and the reinforcement [1]. 


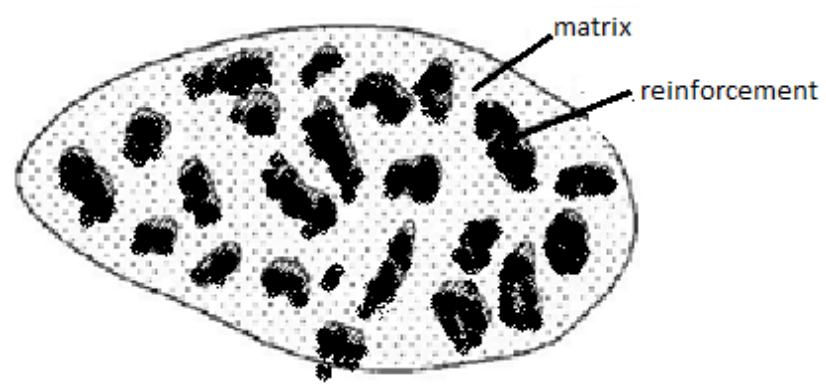

Fig. 1 Simplified scheme of a composite material [1].

There are several criteria for the classification of composite materials [2,3]:

1. Depending on the shape of the two constituents, composite materials can be classified as such:

- Composite materials with particles

- Composite materials with fibers

2. Depending on the nature of the components:

A. Composite materials with organic matrix:

a. With mineral fibers: glass, carbon, etc

b. With organic fibers: Kevlar, polyamides, etc.

c. With metallic fibers: boron, aluminum, etc.

B. Metal matrix composite materials:

a. Mineral fibers: carbon, silicon carbide ( $\mathrm{SiC})$,

b. Metallic fibers: boron

c. Metal-mineral fibers (boron fibers coated with silicon carbide)

C. Composite materials with mineral or ceramic matrix:

a. With metallic fibers: boron

b. With ceramic particles: metalloceramics

c. With mineral particles: carbides, nitrides, etc.

3. Process of realization

A. Wet path:
a. Electrolytic deposits
b. Chemical deposits
c. Recovery deposits

B. Dry path:

a. Chemical vapor deposits: CVD, PVD

b. By projection: flame, arc, plasma, laser.

4. After resistance to the action of atmospheric factors:

a. 4th class: very severe (tropical, marine, corrosive, friction or shock);

b.3rd class: severe (hardware, sanitary ware, etc.);

c.2nd class: moderate (interior vehicle equipment, home appliances);

d.1st class: weak (interior of furniture, toys, radio, television, etc.).

5. Depending on their functional role, deposits can be used as:

a. Organic paints and layers: thermal barrier effect, corrosion protection,

b. Electrolytic and chemical coatings: thermal barrier effect and corrosion protection;

c. Thermal protection: thermal barrier effect and corrosion protection.

d. Immersion in molten metals: thermal barrier effect, corrosion protection, modification of the surface composition.

e. PVD, CVD deposits: barrier effect, corrosion protection.

f. Passivation: barrier effect.

g. Chromatization, phosphating: corrosion protection effect. 
6. Depending on their destination, the deposits may be:

a.Decorative (glossy or matte appearance and special coloring)

b.For corrosion protection

\section{Brief history of composite materials}

A special category in the composite materials class is represented by thin layer deposits. Composite material deposits have a long history in the back. The application of thin deposits of composite materials has been made since Antiquity, where artisanal processes of decoration and protection of surfaces were used with the help of paints. In Egypt and Assyria, sarcophagi, houses, pyramids, etc. were painted with pigments from a mixture of fruit juice (figs) with eggs, honey and wax. The Egyptians were also the first to obtain metal and wood statues that they immersed in concentrated solutions of copper salts (electroplating); they deposited antimony on copper and brass objects [4].

In Thebei area (on the banks of the Nile), the ancient capital of ancient Egypt where the temple complex, chapels, pillars, statuary groups and other constructions, called Karnak, are still found today, two stone obelisks plated with a solution of $75 \% \mathrm{Au}, 22 \% \mathrm{Ag}, 3 \% \mathrm{Cu}$ or electrum, having both anticorrosive protection role and aesthetic role.

From Herodotus we know that the 100 gates that surrounded Babylon built of wood were covered with bronze; thus ensuring protection against atmospheric agents and a pleasant image of them. It was also thanks to him that all the Babylonian buildings were decorated with enamels of different colors, also protective (white enamel oxide based, red enamel $\mathrm{Cu}$ oxide, blue enamel oxide $\mathrm{Co}$, yellow enamel based on antimony) $[4,5]$.

In the Roman Empire counterfeit coins were made, submerging them in the melting basket and mirrors by depositing tin on the copper plate.

Deposits of gold, silver, copper and other metals are also known since ancient times. Thus, the Trandholm Museum (Denmark) owns a solar car dating from the Danish prehistory (1000 years BC) representing a horse that draws a bronze disc plated with gold. The work is made of gold sheets glued with binder and then polished $[4,5]$.

In the sec. in the eleventh century, the Theophile monk describes the practice of mercury gilding; also during this period Alesia points out silver by mixing with mercury for the decoration of weapons and bronze objects. The descriptions made by Herculanum and Pompei show the use of Copper between two silver blades, process resumed in the century. XIII, then in the century. 18th (slightly improved) by a Sheffield knife maker[5].

In time, all these methods have evolved and other new techniques for obtaining composite materials as well as thin layers of composite materials have been discovered. Through this beneficial evolution to the company, deposits with special properties were obtained.

In time, all these methods have evolved and other new techniques for obtaining composite materials as well as thin layers of composite materials have been discovered. Through this beneficial evolution to the company, deposits with special properties were obtained. They have been introduced in all sectors of activity: aeronautics, machine building industry, metallurgy, food industry etc. Deposits with variable thicknesses have been made, protective layers have been deposited on pieces with complicated geometric configuration that give the basic material new properties, capable of meeting the requirements of use (corrosion protection, tribological, optical, thermal, decoration, etc.) [6]. The use of composite materials in a multitude of fields is due to the major advantages that make them the materials of the future.

The advantages of the deposited layers are materialized in:

- They can be obtained by several methods;

- They are lighter: 50\% compared to steel and even 30\% compared to aluminum.

- It has high strength and low weight

- Have high resistance to fatigue and impact

- Investments that are made in the production of small series of parts made of composite materials are smaller than those required to obtain parts from traditional materials; 
- Low density;

- They are easily transported, they are easy to handle;

- Longer life of the covered bodies;

- They are excellent thermal and electrical insulators;

- They have high resistance to chemical corrosion, radiation;

- Have specific aesthetic qualities;

- Have high shock absorption capacity;

- Does not pollute the environment

In order to obtain a deposit that has special properties it is necessary first of all to meet the technical imperatives: protection against corrosion, resistance to friction, wear, high temperatures, hardness, etc., with the satisfaction of operating conditions, maintenance.

For the choice of a deposit, several considerations must be taken into account:

1. The characteristics of the deposit
a. Mechanical characteristics
b. Chemical characteristics
c. Physical characteristics

2. Economic considerations
a. Price
b. Lifetime

3. Nature

a. Components

b. Impurities

c. Methods of application

4. Aspect

\section{CONCLUSION}

Composite materials are materials with remarkable properties, resulting from the combination of two or more homogeneous macroscopic materials, with different structure and properties, which, by combining the individual qualities of the components, form a heterogeneous material with improved overall performance. The possession of these properties gives the composite materials numerous advantages, which cause them to be used in various fields from the aeronautical industry to the food industry and even in the medical field. Being such bidders due to their properties and use, composite materials remain a solution for the replacement of many classic materials, which makes them represent the materials of the future.

\section{References}

[1] http://thesis.univ-biskra.dz/2282/3/ChapI.PDF

[2] M. Pasăre, Structura şi proprietăţile straturilor nickel-fosfor/siliciu carbon electrodepuse pe suport metalic, Editura Sitech, Craiova, ISBN 978-973-746-752-2, 144 pg., 2008

[3] C. Ianasi, Study of the parameters of some reinforced elements, Fiabilitate si Durabilitate Fiability \& Durability No 1/ 2019 Editura “Academica Brâncuşi”, Târgu Jiu, ISSN 1844 640X, pp.73-76.

[4] M. Pasare, Composites-Past and present, Analele Universităţii "ConstantinBrâncuşi”" din Târgu Jiu, Seria Inginerie, Nr. 4/2012, ISSN1842-4856, pg. 193-198

[5] M. Pasăre, L. Luca, R. Dimitrov, Aspects of composite materials evolution, Fiabilitate si Durabilitate - Fiability \& Durability No 2/ 2019 Editura "Academica Brâncuşi”, Târgu Jiu, ISSN 1844 - 640X, 2019, pg. 55-59

[6] M. Pasare, On the applicability of composites materials, Fiabilitate si Durabilitate - Fiability \& Durability No 2/ 2018, Editura "Academica Brâncuşi”, Târgu Jiu, ISSN 1844 - 640X, pg. 83-86 